\title{
The RNA binding domain within the nucleoporin Nup153 associates preferentially with single-stranded RNA
}

\author{
JENNIFER R. BALL, CHRISTIAN DIMAANO, and KATHARINE S. ULLMAN \\ Department of Oncological Sciences, Huntsman Cancer Institute, The University of Utah, Salt Lake City, Utah 84112, USA
}

\begin{abstract}
The nuclear pore protein Nup153 is important for the transport of protein and RNA between the nucleus and cytoplasm. Recently, a novel RNA binding domain (RBD) was mapped within the N-terminal region of Nup153; however, the determinants of RNA association were not characterized. Here we have tested a range of RNAs with different general features to better understand targets recognized by this domain. We have found that the RBD associates with single-stranded RNA with little sequence preference. These results provide new information about a novel RNA binding domain and suggest new models to consider for the contribution of Nup153 to nucleocytoplasmic transport.
\end{abstract}

Keywords: RNA export; RNA binding protein; nuclear pore complex; Nup153

\section{INTRODUCTION}

Eukaryotic cells are distinguished by the presence of multiple organelles that separate cellular functions. Such subcellular division requires biochemical pathways that direct communication between individual cellular compartments. Partitioning of the two main compartments of the cell, the nucleus and cytoplasm, is achieved by a double membrane bilayer termed the nuclear envelope (NE). Although this separation facilitates formation of an environment specialized to maintain and regulate genomic content, it also necessitates that proteins and RNA be transported in a selective manner across the NE. These trafficking events occur through openings in the NE, each formed by a large macromolecular structure, the nuclear pore complex (NPC; for review, see Fahrenkrog and Aebi 2002; Suntharalingam and Wente 2003; Weis 2003).

Characterization of the 30 or so individual components of the NPC provides an important groundwork for understanding NPC function. To this end, we have focused our efforts on the pore protein Nup153. Various experimental strategies have revealed that this nucleoporin plays multifunctional roles in nucleocytoplasmic transport. A role for Nup153 in RNA export was first suggested when overexpression of its C-terminal FG-rich region resulted in

Reprint requests to: Katharine S. Ullman, Department of Oncological Sciences, Huntsman Cancer Institute, The University of Utah, Salt Lake City, UT 84112, USA; e-mail: katie.ullman@hci.utah.edu; fax: (801) 5850900.

Article and publication are at http://www.rnajournal.org/cgi/doi/ 10.1261/rna.5109104. nuclear accumulation of poly(A) ${ }^{+}$RNA (Bastos et al. 1996). Further studies, involving domain-specific Nup153 antibodies injected into Xenopus oocyte nuclei, suggested a role for Nup153 in the export of several classes of RNA (Ullman et al. 1999). This pore protein has also been implicated in nuclear import, with different regions of Nup153 behaving as dominant inhibitors of distinct import pathways (Shah and Forbes 1998). These functional approaches have been complemented by in vitro binding assays to identify interactions between distinct regions of Nup153 and various transport receptors, such as Crm1, TAP, Transportin-1, and Importin $\alpha$ and $\beta$ (Moroianu et al. 1995; Nakielny et al. 1996; Moroianu et al. 1997; Shah and Forbes 1998; Shah et al. 1998; Bachi et al. 2000; Ben-Efraim and Gerace 2001). In addition, a novel RNA binding domain has also been identified in Nup153 (Dimaano et al. 2001).

Although mapping these domains has provided useful information about potential interfaces between Nup153 and transport cargo, more information is clearly needed. One gap in our knowledge is that of whether the RNA binding domain in Nup153 confers a general affinity for RNA or potentially discriminates between different classes of RNA. This information is not readily predictable for two reasons. First, the RNA binding region of Nup153 was originally identified and mapped using homoribopolymers as a tool (Dimaano et al. 2001). Although this provided an unbiased way of detecting such an interaction, it did not provide information on physiological targets. Secondly, because the RNA binding domain in Nup153 shares no apparent homology to known RNA recognition motifs, the sequence of this domain does not yield clues about the nature of the 
RNA target. Thus, to better understand the recognition properties of this novel RNA binding region and to gather information about the interactions in which Nup153 can participate, we have sought to define features of RNA that allow association with Nup153. We have found that the RNA binding domain of Nup153 can selectively recognize single-stranded RNA, independent of orientation. This preferential recognition provides new information about the novel RNA binding domain found in Nup153 and is consistent with a role for this region at the interface between Nup153 and mRNA export cargo.

\section{RESULTS AND DISCUSSION}

\section{Nup153 does not bind structured RNA}

Nup153 was previously shown to stably associate with RNA in vitro (Ullman et al. 1999; Dimaano et al. 2001). Using homoribopolymer $(\mathrm{G})$ as the RNA ligand, a novel domain (amino acids 250-400 in human Nup153) was mapped and found to interact with RNA directly. The ability of this region to associate with RNA is conserved between Drosophila, Xenopus, and human, indicating that this property plays an important functional role in vivo. A Nup153 fragment from this region (referred to throughout as the RBD) was also shown to bind RNA isolated in batch from tissue culture cells; however, the characteristics of the cellular RNAs that bound in this assay were not investigated (Dimaano et al. 2001). To gain insight into how RNA binding contributes to the role of Nup153, we wished to determine whether this novel RNA binding domain has preferred targets and, if so, which population of cellular RNA has the potential to interact with this pore protein.

The observation that poly $(\mathrm{G})$ RNA can adopt structured conformations in solution (Saenger 1984) suggested that Nup153 may interact with RNA targets possessing a distinct conformation. Several classes of structured RNA cargos are transported between the nucleus and cytoplasm during the natural course of their biogenesis. We therefore surveyed a panel of such RNA cargo for their ability to bind the RBD of Nup153. U1 $\Delta \mathrm{Sm}$ and U6 snRNAs are small structured RNA components of the spliceosome. Whereas U6 snRNA is stably sequestered in the nucleus, U1 must initially be exported and then, following specific maturation events, imported to the nucleus to function in splicing. The $\mathrm{U} 1 \Delta \mathrm{Sm}$ construct contains a short (6-nt) deletion in a region between stem-loops $\mathrm{C}$ and $\mathrm{E}$ that is essential for recognition by the import machinery, but it retains its overall structured conformation (Hamm et al. 1987) and is recognized for export. 5S rRNA is a ribosomal RNA and, in oocytes, it is transported as part of an RNP storage particle. Y4 scRNA is a small cytoplasmic RNA normally transcribed by RNA polymerase III and exported to the cytoplasm. Y scRNAs consist of relatively simple stem-loop structures and are thought to be cargos of Exportin-5 (Gwizdek et al.
2001; Rutjes et al. 2001; Gwizdek et al. 2003). These RNAs are surmised to adopt structured conformations when produced by in vitro transcription, based on previous work in the literature (Hamm et al. 1987; Gwizdek et al. 2003).

To test binding, recombinant RBD and a fusion of two tandem GFP proteins (referred to throughout the text simply as GFP) were immobilized on anti-T7-agarose beads followed by incubation with a panel of RNAs labeled during in vitro transcription. To reduce nonspecific interactions, binding was performed in the presence of heparin sulfate and the pellet was extensively washed. Following binding and washing, the agarose beads were divided and subjected to protein and RNA analysis. Protein was eluted from onehalf of the beads with SDS loading buffer and was analyzed by Western blot with an antibody directed against the T7 epitope tag on the RBD and GFP. RNA was extracted from the other half of the beads after ${ }^{32} \mathrm{P}$-labeled tRNA was added as a tracer for RNA recovery. RNA purified from this fraction was then analyzed on a denaturing gel. Unbound RNA was similarly isolated from the supernatant to assure that it was not subject to degradation during the assay.

Analysis of the RNA in the supernatant (Fig. 1A, lanes 1,2 , upper panel) revealed that all RNAs in the input (Fig. $1 \mathrm{~A}$, lane 5, upper panel) were indeed intact throughout the binding procedure. However, only the recovery control (tracer) RNA was detected in the pellet (Fig. 1A, lanes 3,4, middle panel) suggesting that under these conditions, which were previously used to demonstrate that cellular RNA could bind the RBD (Dimaano et al. 2001), the RBD does not associate with the structured RNA cargos tested. Western analysis confirmed recovery of both the RBD and GFP (Fig. 1A, lanes 3,4, lower panel).

\section{The RNA binding domain of Nup153 associates with single-stranded but not double-stranded RNA}

An alternative possibility that we considered was whether Nup153 might recognize an extended double-stranded stretch of RNA, another structure that poly $(\mathrm{G})$ can mimic and one which is found in cellular RNAs as well (Morse et al. 2002). Because the RNA cargos tested above are not predicted to have extended helical structures, we specifically generated and tested such an RNA target. Chloramphenicol acetyl transferase mRNA (CAT) was transcribed in both the sense and antisense orientation and the two strands were then annealed to produce dsRNA. The single- and doublestranded populations of CAT RNA are readily resolved by native polyacrylamide gel electrophoresis (PAGE) because the more compact double-stranded RNA exhibits faster mobility than its single-stranded counterpart.

To determine if dsRNA associates with Nup153, the RBD and GFP were each immobilized on anti-T7-agarose beads and either single-stranded RNA or double-stranded RNA was incubated with the immobilized proteins in the presence of heparin sulfate. Analysis was performed as described 
A

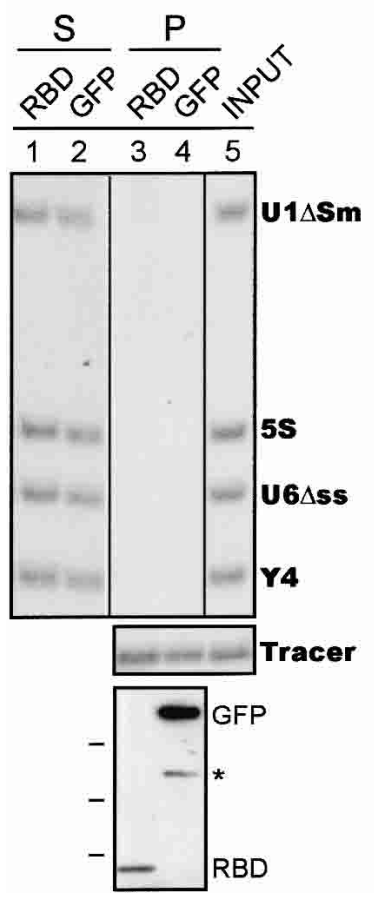

B

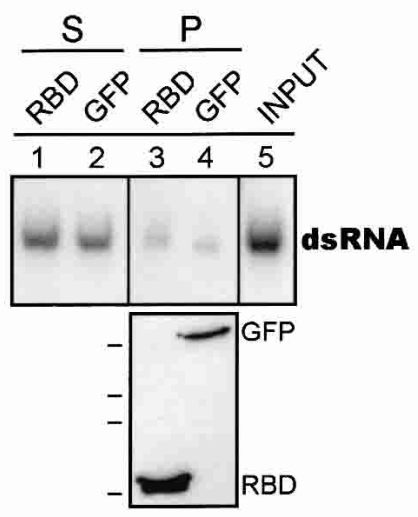

C

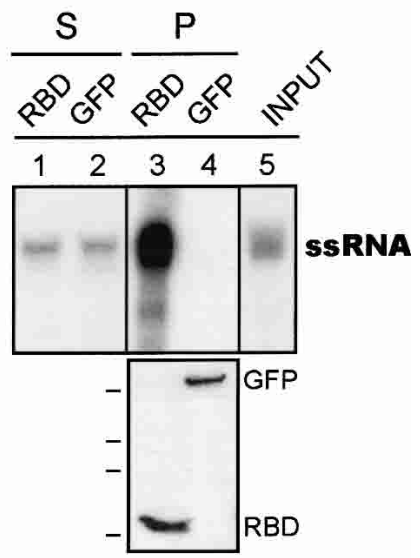

FIGURE 1. The RNA binding domain of Nup153 preferentially associates with single-stranded RNA. (A) Recombinant T7-tagged RBD and GFP were immobilized on anti-T7-agarose beads followed by incubation with a panel of structured ${ }^{32} \mathrm{P}$-labeled RNAs (lane 5). RNA was isolated from the supernatant $(\mathrm{S}$; lanes 1,2$)$ and the pellet (P; lanes 3,4) of each reaction. tRNA (tracer) was added to the RNA pellet fractions following the washes to monitor RNA recovery (lanes 3-5, middle panel). Protein recovery was determined by Western blotting with an anti-T7 antibody (lanes 3,4 , lower panel). The size markers on the left represent 52, 34, and $28 \mathrm{kD}$, respectively. The asterisk represents a degradation product of the GFP fusion protein. (B) A binding assay was performed as above with ${ }^{32} \mathrm{P}$-labeled double-stranded CAT RNA (input, lane 5). Unbound RNA (S) was compared to bound RNA (P; cf. lanes 1,2 and 3,4). Protein recovery was confirmed by T7 Western blot (lower panel). In B and C, the size markers on the left represent $48,34,28$, and $21 \mathrm{kD}$. (C) A binding assay was performed as above with ${ }^{32} \mathrm{P}$-labeled single-stranded CAT mRNA (input, lane 5). Unbound RNA (S) was compared to bound RNA (P; cf. lanes 1,2 and 3,4). Protein recovery was confirmed by T7 Western blot (lower panel). In all experiments, $50 \%$ of bound RNA, $4 \%$ of unbound RNA, and $2 \%$ of the input was loaded on each gel.

above except that the isolated RNA was subjected to native PAGE. Unexpectedly, whereas dsRNA did not associate appreciably with the RBD (Fig. 1B, lane 3, upper panel), single-stranded RNA bound relatively robustly (Fig. 1C, lane 3, upper panel). In both cases, the unbound RNA isolated from the supernatant was comparable between samples (Fig. 1B, lanes 1,2, and Fig. 1C, lanes 1,2), indicating that degradation and/or double-stranded to singlestranded conversion did not occur. Under these conditions, the amount of RNA bound to recombinant protein does not deplete the input material. Protein recovery was confirmed to be equivalent between various samples (Fig. 1B, lanes 3,4, and Fig. 1C, lanes 3,4, lower panels). Together, these results suggest that the RBD distinguishes between different types of RNA and that single-stranded RNA is the preferred ligand.

\section{The Nup153 RNA binding domain has a generic preference for single-stranded RNA}

Having discovered that the Nup153 RBD binds singlestranded RNA, we next addressed whether the recognition is based on the single-stranded nature of RNA or whether there is a cryptic motif in CAT RNA that mimics a specific recognition element. Full-length Nup153 was produced and purified from bacteria, immobilized on anti-T7-agarose beads, and, as before, incubated with a mix of ${ }^{32} \mathrm{P}$-labeled RNAs in the presence of heparin sulfate. In addition to CAT mRNA, two other RNAs, DHFR (encoding dihydrofolate reductase) and $\mathrm{Ad} \Delta \mathrm{i}$ (an intronless version of mRNA derived from adenovirus major late transcript), were included. These are routinely used to represent mRNA export cargo in transport studies and are not predicted to adopt a stable secondary conformation. Structured RNA cargos were included in the same panel for direct comparison. After binding, the pellet was extensively washed and split as before to assess protein and RNA recovery. Fulllength Nup153 was detected by immunoblotting with an antibody reactive with the carboxy-terminal region of Nup153 (Fig. 2A, lane 1, lower panel).

Full-length Nup153 exhibited the same preference as the isolated RBD, binding CAT mRNA over structured RNAs (Fig. 2A, lane 1). In addition, DHFR mRNA bound equally well as CAT mRNA to Nup153. Ad $\Delta \mathrm{i}$ was not efficiently 
recovered in association with Nup153 (Fig. 2A, lane 1), raising the issue of whether the interaction between Nup153 and mRNA is influenced by the length of the RNA target
A

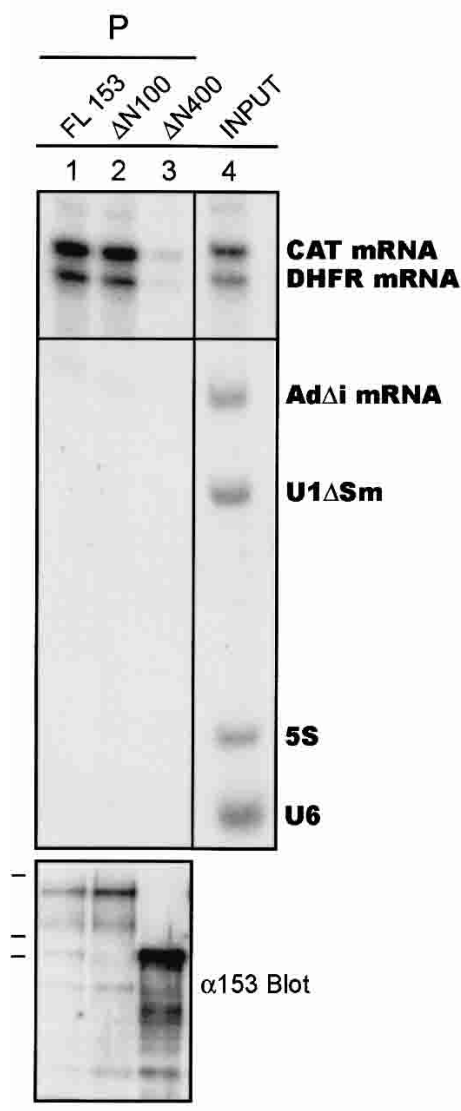

B

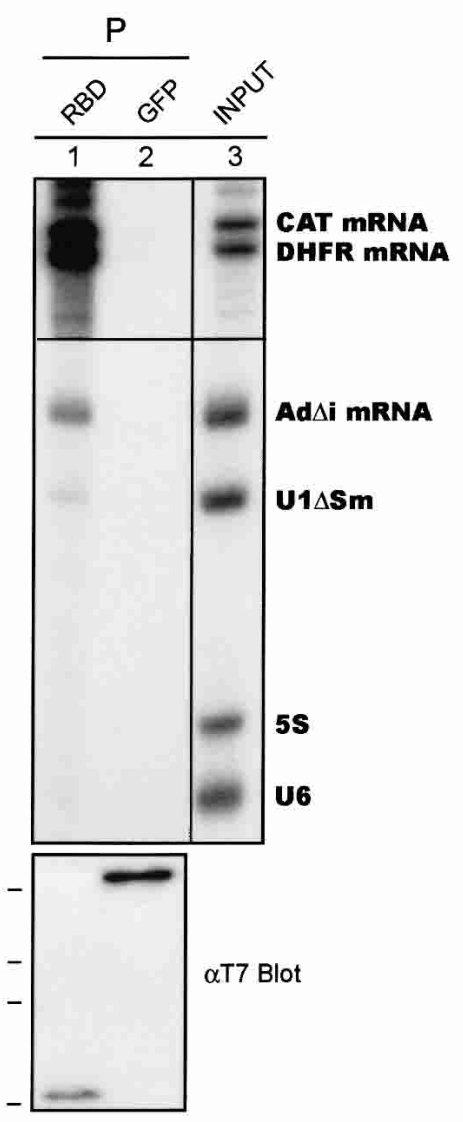

C

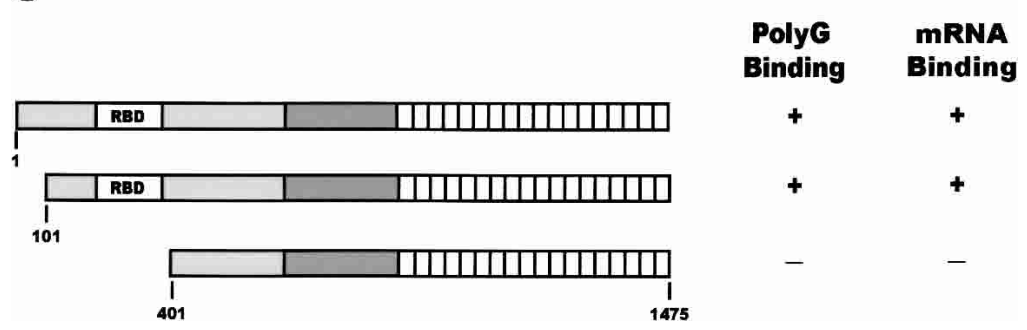

FIGURE 2. The Nup153 RNA binding domain, whether in isolation or in its full-length context, recognizes features common to mRNAs. (A) Recombinant T7-tagged full-length Nup153 and truncated version containing a deletion of either the first 100 and 400 amino acids

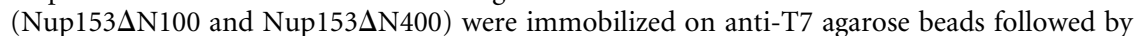
incubation with ${ }^{32} \mathrm{P}$-labeled RNA cargo (lane 4$)$. RNA remaining in the final pellet $(\mathrm{P})$ is shown for each recombinant protein (lanes 1-3, upper panel). For A and B, RNA was loaded as described in Figure 1. Immobilized protein was detected using mAb414 (lanes 1-3, lower panel). The size indicators to the left represent 203, 115, and $93 \mathrm{kD}$. (B) Recombinant T7tagged RBD and GFP were immobilized on anti-T7-agarose followed by incubation with ${ }^{32} \mathrm{P}$-labeled RNA cargo (lane 3). RNA remaining in the final pellet (P) is shown in the upper panel (lanes 1,2). Immobilized protein was detected with an anti-T7 antibody (lanes 1,2, lower panel). The size indicators to the left represent 48, 34, 28, and $21 \mathrm{kD}$. (C) Shown is a schematic depicting full-length Nup153, N-terminal deletion constructs in relation to the RNA binding domain (white box labeled RBD), the zinc finger region (dark gray shading), and FG-rich region (white box with black hatch marks). The poly $(\mathrm{G})$ binding and mRNA binding for these constructs is summarized at the right. (respective lengths are listed in Materials and Methods). Although its association clearly appeared less efficient than RNAs, $\operatorname{Ad} \Delta \mathrm{i}$ could be seen on longer exposures of pull-downs of fulllength Nup153 (data not shown), Nup153 $\Delta$ N100 (e.g., Fig. 3A, lane 1) and on shorter exposures in the case of the RBD pull-downs (Fig. 2B, lane 1), where there was an overall increase in RNA recovery compared to full length. GFP, which serves as a negative control, does not bind to any RNA tested (Fig. 2B, lane 2).

Together, these results indicate that the RBD of Nup153 recognizes general features of unstructured RNA. To test this hypothesis further, we surveyed several other RNAs, including mRNAs that encode $\beta$-galactosidase, apobec- 1 and apobec-1 complementation factor (templates were kind gifts of Dr. V. Blanc, Washington University). In each case, we found that, despite their overall heterogeneity, all of these RNAs bound the Nup153 RBD with efficiency similar to that of DHFR and CAT mRNA (data not shown). It is unlikely that there is a cryptic recognition element in each of these independent mRNAs. However, it is possible that the Nup153 RBD interacts preferentially with a sequence enriched in a particular base composition. This possibility is consistent with the influence of length on binding because increased length would correspond to a greater probability of containing such a region. It is also consistent with our observation that short, single-stranded RNAs associate with Nup153 RBD significantly better than structured RNAs in the same size range, but display more heterogeneity in their binding ability than longer single-stranded substrates (Fig. 3B). A base composition bias would also be consistent with the previous observation that Nup153 preferentially associates with poly $(\mathrm{G})$ compared to other homoribolymers (Ullman et al. 1999). Interestingly, a size constraint has also been observed for mRNA export in the case where splicing has not taken place (Luo and Reed 1999; Rodrigues et al. 2001). Ad $\Delta \mathrm{i}$, in fact, is an example of a small mRNA that exhibits little to no export when injected into oocytes, indi- 
A

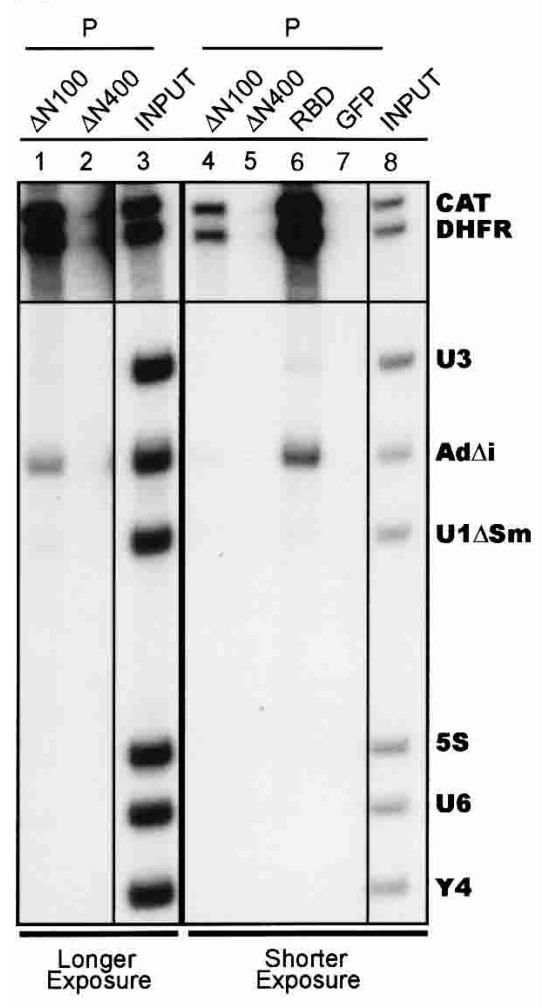

B

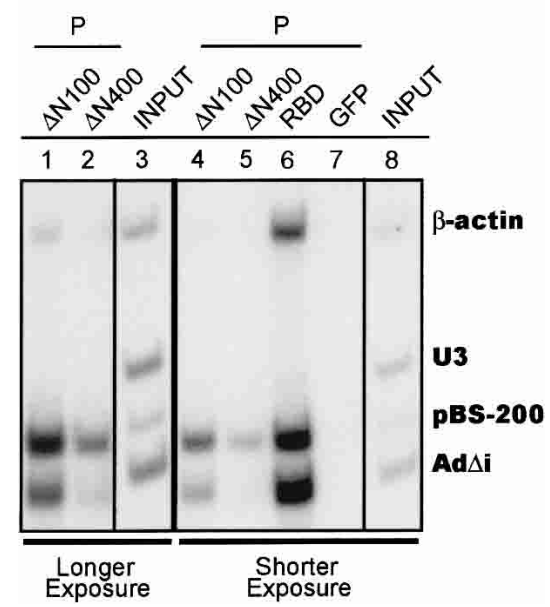

FIGURE 3. The Nup153 RNA binding domain preferentially binds unstructured RNA. Recombinant T7-tagged Nup153 $\Delta$ N100, Nup153 $\Delta$ N400, Nup153 RBD, and GFP were immobilized on anti-T7 agarose. $(A)^{32} \mathrm{P}$-labeled RNAs, including a broad size range of singlestranded RNAs and structured RNAs (lane 8) were incubated with immobilized protein. Following washes, bound RNA (P) was isolated from the pellet (lanes 1,2,4-7). RNA samples were loaded as described in Figure 1. Two exposures of the pull-down of RNA with

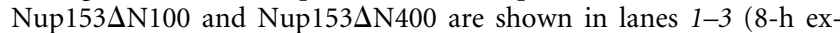
posure at room temperature labeled longer exposure) and lanes 4-8 (30 min exposure at $-80^{\circ} \mathrm{C}$ labeled shorter exposure). (B) ${ }^{32} \mathrm{P}$-labeled RNAs, including a narrow size range of single-stranded mRNAs and the structured U3 RNA were incubated with immobilized protein. Following washes, the bound RNA was isolated from the pellet (lanes $1,2,4-7)$. RNA samples were loaded as described in Figure 1. Two exposures of the pull-down of RNA with Nup153 $\Delta$ N100 and Nup153 $\Delta \mathrm{N} 400$ are shown in lanes $1-3\left(22-\mathrm{min}\right.$ exposure at $-80^{\circ} \mathrm{C}$ labeled longer exposure) and $4-8\left(15-\mathrm{min}\right.$ exposure at $-80^{\circ} \mathrm{C}$ labeled shorter exposure). cating that the mRNA export machinery does not recognize it efficiently (Luo and Reed 1999).

\section{Full-length Nup153 associates with single-stranded RNA in a RBD-dependent manner}

To determine whether the RBD accounts for the direct RNA binding ability of full-length Nup153, we took advantage of a series of $\mathrm{N}$-terminal truncations. When this series was used previously, deletion of 100,200 , or 300 amino acids from the $\mathrm{N}$ terminus of Nup153 did not dramatically affect poly $(\mathrm{G})$ binding, whereas deletion of 400 amino acids impaired recovery of Nup153 with the homoribopolymer matrix (Dimaano et al. 2001). In this case, key constructs were produced as recombinant proteins and the binding of physiological RNA was monitored. Deleting the first 100 residues of Nup153 did not affect the pattern of RNA association (Fig. 2A, lane 2), but deleting an additional 300 residues, which removes the previously defined RBD, eliminated the ability of Nup153 to bind these particular RNAs (Fig. 2A, lane 3). These results demonstrate that full-length Nup153 can preferentially associate with single-stranded RNA via contacts with the RNA binding domain in the N-terminal region of Nup153 (amino acids 250-400; Fig. 2C). We have also tested whether recombinant Nup153 RBD can associate with double-stranded DNA and have found no significant interaction (data not shown). In contrast, preliminary analysis suggests that Nup153 has affinity for single-stranded DNA (data not shown). Although we have not yet characterized this interaction or quantitatively compared binding of single-stranded RNA and DNA, this general property, which is shared by other RNA binding proteins (Pinol-Roma et al. 1988), raises interesting possibilities for future investigation.

\section{Lack of secondary structure, and not length alone, is important for recognition by the Nup153 RNA binding domain}

In the aforementioned RNA mixes, the structured RNAs (with the exception of dsRNA) were shorter than the mRNAs (approximately 90-150 versus 250-800 nt, respectively). Although this trend is generally true for RNA export cargo, it left open the possibility that total length of the RNA is the main determinant for Nup153 association. To address this, the binding of U3 snRNA, a structured RNA (Marmier-Gourrier et al. 2003) that is longer than $\operatorname{Ad} \Delta \mathrm{i}$, was tested. Recombinant Nup153 $\Delta$ N100, Nup153 $\Delta$ N400, $\mathrm{RBD}$, and GFP were immobilized and RNAs were tested for association.

The Nup153 NN100 and RBD fragment bound to all unstructured mRNAs tested but did not bind to the structured U3 snRNA or other structured RNAs in the panel (Fig. 3A, lanes $1,4,6)$. As expected, the $\Delta \mathrm{N} 400$ fragment of Nup153, which is missing the RNA binding domain, and GFP fusion 
protein did not bind RNA (Fig. 3A, lanes 2,5,7). Note that lanes 1-3 in Figure 3A are a longer exposure of lanes 4, 5, and 8 . The smaller mRNA, $A d \Delta \mathrm{i}$, and not the larger structured RNA, U3, associated with both the RBD and $\triangle \mathrm{N} 100$ fragment, albeit more weakly in the latter case. We further probed the binding ability of RNAs in this smaller size range by including two additional single-stranded RNAs, one smaller (plasmid derived, designated pBS-200) and one larger ( $\beta$-actin) than U3 snRNA. Both single-stranded RNAs clearly associate with Nup153 RBD to a far greater degree than does U3 (Fig. 3B, lane 6). The same binding profile is seen with $\Delta \mathrm{N} 100$, but not $\Delta \mathrm{N} 400$ (Fig. $3 \mathrm{~B}$, lanes 1,2, longer exposure, and lanes 4,5 , shorter exposure). This observation reinforces the notion that Nup153 discriminates between types of RNA based on the single-stranded nature of the RNA rather than fortuitous length of the ligand. At the same time, as mentioned above, the varying degree to which shorter, single-stranded RNAs bind indicates that total length and/or a sequence composition bias is a contributing factor to the efficiency of RNA recognition by Nup153.

\section{mRNA export and the association between the RBD of Nup153 and mRNA are orientation-independent}

Recent work by Mattaj and colleagues has functionally defined features of mRNA that allow it to be recognized by the nuclear export machinery. Using U1-mRNA hybrid transcripts, it was determined that mRNA inserted into U1 was able to direct the U1 hybrid into a Crm1-independent mRNA export pathway. The general defining feature of mRNA that directs this switch was found to be an unstructured stretch of RNA of sufficient length, independent of RNA orientation (Ohno et al. 2002; Ullman 2002). We predicted that if factors directing mRNA export do not distinguish between sense and antisense, then mRNA in either orientation should be exported from the nucleus with the same efficiency. Moreover, if RNA binding by Nup153 is part of the cargo recognition process for mRNA export, this binding should be orientation independent as well.
A

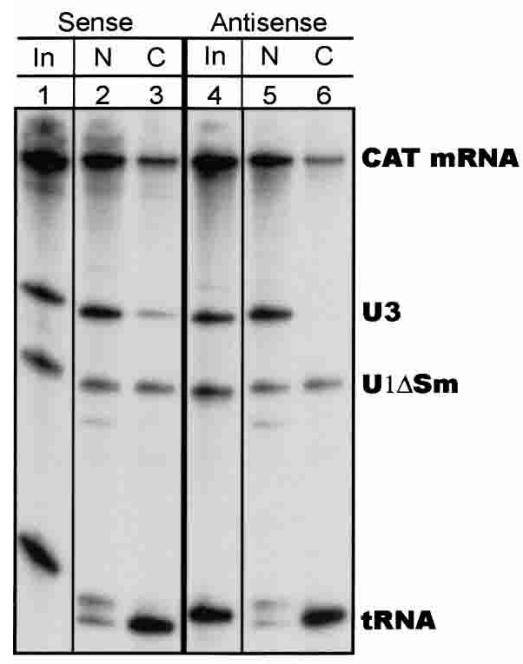

C

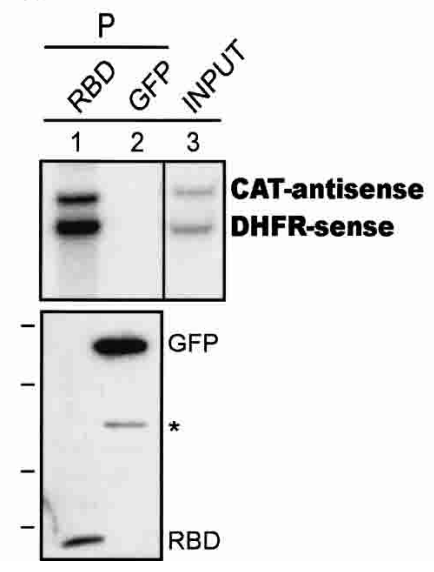

B

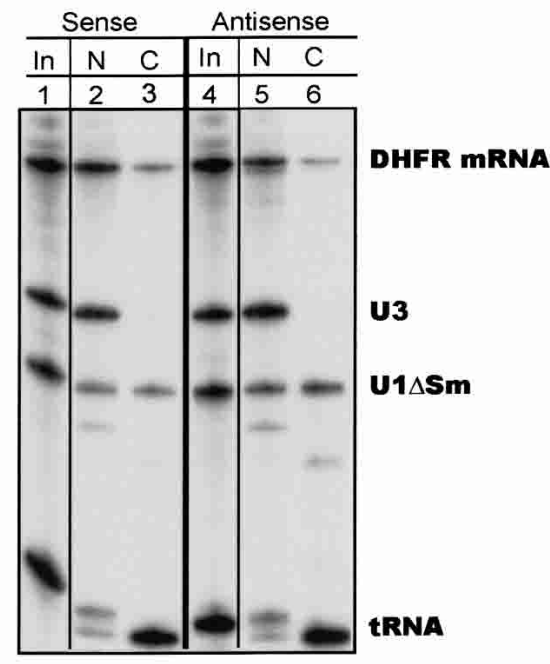

To first test whether mRNA export is, in fact, independent of orientation, ${ }^{32} \mathrm{P}$-labeled sense and antisense CAT (Fig. 4A) and DHFR mRNA (Fig. 4B) were injected into Xenopus oocyte nuclei and the extent of export determined after $4 \mathrm{~h}$ by microdissection of nuclear and cytoplasmic populations. U3 snRNA, which serves as a control for nuclear injections and dissections, was included in the RNA

FIGURE 4. RNA recognition, like export, is independent of mRNA orientation. (A) Xenopus oocyte nuclei were injected with $10 \mathrm{~nL}$ of either sense or antisense CAT mRNA mix containing $\mathrm{U} 3, \mathrm{U} 1 \Delta \mathrm{Sm}$, and tRNA as controls (lanes 1,4 ). Oocytes were dissected $4 \mathrm{~h}$ postinjection. RNAs remaining in the nucleus (lanes 2,5) or exported to the cytoplasm are shown (lanes 3,6$)$. $(B)$ Xenopus oocyte nuclei were injected as above except that DHFR-sense or DHFR-antisense mRNA was added to the RNA mix. Nuclear RNAs (lanes 2,5) and RNAs exported to the cytoplasm (lanes 3,6) are shown. (C) Nup153 RBD and GFP were immobilized on anti-T7agarose. A mix of RNAs, including either ${ }^{32} \mathrm{P}$-labeled CAT-sense with DHFR-antisense mRNA (lane 3) or CAT-antisense with DHFR-sense mRNA (lane 6), were incubated with immobilized protein. After washing, the bound RNA was isolated from the pellet (P; cf. lanes 1,2 and 4,5, upper panels). RNA samples were loaded as described in Figure 1. RNA from the pellet was exposed to film for $2 \mathrm{~h}$ (lanes 1,2,4,5) whereas the input RNA was exposed to film for $4 \mathrm{~h}$ (lanes $3,6)$. Protein recovery was determined by Western blotting with an anti-T7 antibody (lanes $1,2,4,5$, lower panel). The size markers at the left represent 90, 52, 34, and $28 \mathrm{kD}$. The asterisk on the right represents a breakdown product of the GFP fusion.

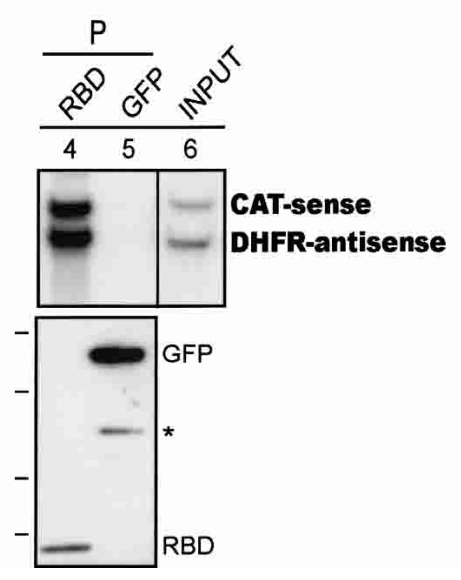

RNA, Vol. 10, No. 1 
mix. U1 $\Delta \mathrm{Sm}$ and tRNA were also included in the mix as positive controls for export. Both the sense and antisense transcripts of CAT and DHFR mRNA were exported from the nucleus at comparable efficiency (Fig. 4A, cf. lanes 3 and 6; Fig. 4B, cf. lanes 3 and 6). This demonstrates that, for the purpose of packaging and exporting an mRNP, the molecular machinery involved does not discriminate between the sense and antisense orientation.

To address whether Nup153 can associate with mRNA independent of orientation, the Nup153 RBD and GFP were immobilized on anti-T7-agarose beads and incubated with ${ }^{32} \mathrm{P}$-labeled sense and antisense CAT and DHFR mRNA as described earlier. The RBD was found to bind similarly to CAT sense and antisense mRNA, and DHFR-sense and antisense mRNA (Fig. 4C, cf. lanes 1 and 4). The GFP negative control did not associate with either mRNA population (Fig. 4C, lanes 2,5).

\section{CONCLUSIONS}

Together, this new data demonstrates that Nup153 contains a bona fide RNA binding domain. More specifically, this region within Nup153 mediates preferential binding to single-stranded RNA that is independent of orientation and influenced by the length of the RNA. With this information in hand, it will be important to assess the specific contribution of this binding ability to the function of Nup153. Interestingly, these parameters of RNA recognition by Nup153 mirror the functional definition of mRNA with respect to export. This is also particularly intriguing in light of the recent observation that inhibition of RNA polymerase II interferes with Nup153 mobility (E. Griffis, B. Craige, C. Dimaano, K.S. Ullman, and M. Powers, in prep.). In addition to probing the functional contribution of RNA binding, further studies will be needed to address how RNA binding is integrated with the other interactions involving Nup153. Finally, given the lack of homology to known RNA binding domains, the underlying structural basis for this RNA recognition property will be of interest.

\section{MATERIALS AND METHODS}

\section{Cloning and purification of recombinant proteins}

Constructs encoding Nup153, Nup153 $\Delta 100$, and Nup153 $\Delta 400$ (Dimaano et al. 2001) were expressed in BL21(RIL) cells (Stratagene). Overnight cultures were diluted (1:20) and grown until the O.D. 600 was $0.8-1.0$. Expression of protein was induced by $1 \mathrm{mM}$ isopropyl-1-thio- $\beta$-D-galactopyranoside for $3 \mathrm{~h}$ at $37^{\circ} \mathrm{C}$. Bacterial pellets were resuspended in lysis buffer $(0.5 \mathrm{M} \mathrm{NaCl}, 20 \mathrm{mM}$ Tris at $\mathrm{pH} 8,5 \mathrm{mM}$ imidazole, $1 \mathrm{mg} / \mathrm{mL}$ lysozyme) and sonicated $4 \times$ for $30 \mathrm{sec}$ at $4^{\circ} \mathrm{C}$. After overnight incubation $\left(4^{\circ} \mathrm{C}\right)$ with lysate, nickel-NTA beads (Qiagen) were washed twice with buffer $(0.5 \mathrm{M}$ $\mathrm{NaCl}, 20 \mathrm{mM}$ Tris at $\mathrm{pH}$ 8) containing $20 \mathrm{mM}$ imidazole. Protein was eluted from the beads with $5 \mathrm{~mL}$ of buffer containing $250 \mathrm{mM}$ imidazole for $20 \mathrm{~min}$ at room temperature.
The construct encoding a fragment overlapping the Nup153 RBD was previously described (Dimaano et al. 2001). This construct encodes Xenopus Nup153 residues 249-375. Although the minimal RBD was mapped to residues $260-410$ of Nup153, the RBD fragment used in these studies was shown previously to retain substantial RNA binding activity. The construct encoding GFP was made by cloning two copies of the GFP gene into the pET28 vector. To simplify the text, this double GFP fusion is referred to as GFP. The RBD and GFP proteins were produced and purified as previously described (Dimaano et al. 2001).

\section{Transcription templates and in vitro transcription}

To clone the gene encoding Y4 RNA, two 122-mer oligonucleotides corresponding to the sense and antisense strands of $\mathrm{Y} 4$ (GenBank accession number X57566) and sites required for cloning and transcription were synthesized: (Y4 sense oligo is $5^{\prime}$-cgc ggatccttt-[Y4 gene]-tttaaaggatcccg-3' and Y4-antisense oligo is $5^{\prime}$-cgcggatccttt-[Y4 antisense]-tatagtgagtcgtattagaattccgg- $3^{\prime}$. Fulllength oligos were gel purified and denatured for $5 \mathrm{~min}$ at $95^{\circ} \mathrm{C}$ before annealing overnight in $1 \times$ Klenow Buffer at room temperature. The annealed oligos were cut with EcoRI and BamHI, gel purified, and ligated into pUC19. A tRNA template was constructed by PCR amplifying the human tRNA met $_{\text {gene (with oligos }}$ 5' -TAATACGACTCACTATAGGGAGCCAGAGTGGCGCAGC, 5' GGAAGCTTAGCAGAGGATGGTT; template a kind gift of Dr. Michael Zasloff, Georgetown University), TA cloning an intermediate in pCR2.1, and then moving the gene into the HindIII to XbaI sites of pUC19. A transcription template for U6 was constructed following a similar strategy for the Xenopus tropicalis U6 gene (oligos 5'-TAATACGACTCACTATAGGTGCTTGCTTCGGC, 5' -GGTT TAAAAATATGGAACGCTTCAC; template a gift of Dr. Elsebet Lund, University of Wisconsin). The Xenopus laevis U3 snRNA gene was amplified with primers and template kindly provided by Dr. Elsebet Lund. An MscI site was introduced downstream from the U3 gene by a second round of PCR using a different $3^{\prime}$ primer (5'-TGGCCACTCAGCTTGTGTTC). This new product was TA cloned into pCR2.1 (Invitrogen). The templates for CAT sense and antisense were kind gifts of Dr. Brenda Bass, University of Utah. The template encoding $\operatorname{Ad} \Delta \mathrm{i}$ was a kind gift of Dr. Robin Reed, Harvard University. Templates for $5 S$ and DHFR were as previously described (Ullman et al. 1999). The template for DHFR antisense was cloned as described for the sense construct (Ullman et al. 1999). Each template was linearized with the appropriate enzyme before using in in vitro transcription reactions (CAT sense and antisense with BamHI, DHFR sense and antisense with XbaI, tRNA with HindIII, Ad $\Delta$ i with BamHI, U6, Y4, and 5S with DraI, and U3 with $M s c I$ ). A transcription template for pBS-200 was PCR amplified from pBluescript (Stratagene; oligos 5'-CGCCAG GGTTTTCCCAGTCAC-3' and 5'-GACACACTTTAACAATAG GC- $3^{\prime}$ ). The p-TRI-actin-mouse (Ambion) template was used to generate single-stranded $\beta$-actin in the antisense orientation. The respective sizes of the RNAs used in these experiments were as follows: CAT, $\sim 800 \mathrm{nt}$; DHFR, $564 \mathrm{nt} ; \beta$-actin, $276 \mathrm{nt}$; U3, $219 \mathrm{nt}$; pBS-200, 200 nt; Ad $\Delta$ i, 195 nt; U1 $\Delta$ Sm, 160 nt; 5S, 115 nt; U6, 107 nt; Y4, $96 \mathrm{nt}$; and tRNA, $75 \mathrm{nt}$.

Radiolabeled RNAs were generated by using the MaxiScript in vitro transcription kit (Ambion) in the presence of ${ }^{32} \mathrm{P}$-UTP. In the case of U1 snRNA, U3 snRNA, and mRNAs, the $\mathrm{m}^{7} \mathrm{CAP}$ analog was also included. SP6 was used to generate CAT-sense, CAT- 
antisense, $\mathrm{U} 1 \Delta \mathrm{Sm}, \mathrm{U} 6$, and $\mathrm{U} 3$, and $\mathrm{T} 7$ was used to generate DHFR-sense, DHFR-antisense, pBS-200, Ad $\Delta \mathrm{i}, 5 \mathrm{~S}, \mathrm{Y} 4$, and tRNA. T3 polymerase (Promega) was used to generate $\beta$-actin. Unincorporated ${ }^{32} \mathrm{P}$-GTP was removed from the transcription reaction by either ethanol precipitation or by centrifugation through G50 spin columns (Pharmacia).

\section{RNA binding assay}

Anti-T7 agarose beads (Novagen) were equilibrated in binding buffer $(100 \mathrm{mM} \mathrm{KCl}, 25 \mathrm{mM}$ HEPES at $\mathrm{pH} 7.6,0.5 \%$ Triton $\mathrm{X}-100$ ) and blocked with $10 \mathrm{mg} / \mathrm{mL}$ bovine serum albumin (BSA Fraction V, Sigma) for $1 \mathrm{~h}$ at room temperature. T7-tagged recombinant proteins were then incubated with the beads for $1 \mathrm{~h}$ at $4^{\circ} \mathrm{C}$. In the case of RBD and GFP, $250 \mathrm{ng}$ of protein were used per reaction. In the case of full-length and truncated Nup153, recombinant protein was normalized to Xenopus egg extract by mAb414 reactivity on Western blot and the amount equivalent to $20 \mu \mathrm{g}$ of egg extract was used in each reaction. Immobilized protein on the beads was washed twice with Binding Buffer and ${ }^{32} \mathrm{P}$-labeled RNA was then added in the presence of Binding Buffer, $3 \mathrm{mg} / \mathrm{mL}$ heparin sulfate (Calbiochem) and 40 units RNasin (Promega). After incubation for $1 \mathrm{~h}$ at $4^{\circ} \mathrm{C}$, the beads were washed $3 \times$ with $200 \mathrm{mM}$ $\mathrm{KCl}, 25 \mathrm{mM}$ HEPES (pH 7.6), 0.5\% Triton X-100. During the last wash, the beads were divided equally.

For RNA isolation, $200 \mu \mathrm{L}$ NTS buffer $(300 \mathrm{mM} \mathrm{NaCl}, 100 \mathrm{mM}$ Tris at $\mathrm{pH} 8,2 \%$ SDS) were added to the beads and to the unbound fraction. As a control for RNA recovery, ${ }^{32} \mathrm{P}$-labeled tRNA was included in the NTS that was added to the beads. The samples were extracted at $37^{\circ} \mathrm{C}$ with phenol-chloroform-isoamyl alcohol ( $\mathrm{pH} 4.5)$ and then ethanol precipitated. RNA was resuspended in $10 \mathrm{M}$ Urea/1× TBE and resolved on a denaturing $6 \%$ acrylamide gel. When binding of double-stranded and single-stranded RNAs were being compared, the RNA was resuspended in $1 \times$ TBE native RNA loading buffer ( $0.6 \mathrm{M}$ Sucrose, $0.1 \times$ TBE, $0.5 \% \mathrm{SDS})$ and resolved on a native $4 \%$ acrylamide gel. Fifty percent of the bound RNA, $4 \%$ of the unbound RNA, and $2 \%$ of the RNA input was loaded on each gel.

To determine protein recovery in the bound fraction, $2 \times$ SDS loading buffer was added to the other half of the beads. The RBD and GFP samples were resolved on a 12\% SDS-PAGE gel and detected with an anti-T7 antibody (Novagen). Full-length and truncated forms of Nup153 were resolved on 6\% SDS-PAGE gels and detected with mAb414 (Covance).

\section{Oocyte injection and analysis of export}

Oocytes were isolated and injected following standard procedures (Duricka and Ullman 2001). Rhodamine dextran (3-5 mg/mL; Molecular Probes) was included with the radiolabeled RNA export substrates to visualize injected nuclei during dissection. Injected oocytes were incubated for $4 \mathrm{~h}$ at $18^{\circ} \mathrm{C}$ and then transferred to mineral oil for manual dissection. Nuclear and cytoplasmic fractions in RNA harvest buffer $(100 \mathrm{mM}$ Tris at $\mathrm{pH} 7.6,10 \mathrm{mM}$ EDTA at $\mathrm{pH} 8,500 \mathrm{mM} \mathrm{NaCl}, 2 \%$ SDS) were extracted with acid phenol-chloroform. RNA was precipitated with ethanol in the presence of seeDNA (Amersham) as a carrier. Pellets were resuspended in $80 \%$ formamide, $10 \mathrm{mM}$ EDTA $(\mathrm{pH} 8)$ and heated to $70^{\circ} \mathrm{C}$ for $10 \mathrm{~min}$. The amount equivalent to approximately one oocyte nucleus or cytoplasm was loaded into each lane of a $6 \%$ denaturing acrylamide gel. Following electrophoresis, gels were fixed, dried, and analyzed by autoradiography.

\section{ACKNOWLEDGMENTS}

We thank Brian Bennion for his expert technical assistance, Deborah Duricka and Tracy Zundel for constructing plasmids and transcription templates, and those listed in the text for providing reagents. We also thank Jacqui Wittmeyer and Valerie Blanc for helpful advice and critical reading of the manuscript. In addition, we extend gratitude to Nicholas Davidson for providing a stimulating environment where some of this work was completed. We thank the DNA Synthesis and DNA Sequencing Core Facilities at the University of Utah (partially supported by National Institutes of Health grant P30 CA42014). This work was supported by National Institutes of Health Grant GM61275, a Burroughs Wellcome Career Award in Biomedical Science (to K.S.U.), and a Ruth L. Kirschstein Individual National Research Service Award (to C.D.).

The publication costs of this article were defrayed in part by payment of page charges. This article must therefore be hereby marked "advertisement" in accordance with 18 USC section 1734 solely to indicate this fact.

Received June 18, 2003; accepted September 22, 2003.

\section{REFERENCES}

Bachi, A., Braun, I.C., Rodrigues, J.P., Pante, N., Ribbeck, K., von Kobbe, C., Kutay, U., Wilm, M., Gorlich, D., Carmo-Fonseca, M., et al. 2000. The C-terminal domain of TAP interacts with the nuclear pore complex and promotes export of specific CTE-bearing RNA substrates. RNA 6: 136-158.

Bastos, R., Lin, A., Enarson, M., and Burke, B. 1996. Targeting and function in mRNA export of nuclear pore complex protein Nup153. J. Cell. Biol. 134: 1141-1156.

Ben-Efraim, I. and Gerace, L. 2001. Gradient of increasing affinity of importin $\beta$ for nucleoporins along the pathway of nuclear import. J. Cell. Biol. 152: 411-417.

Dimaano, C., Ball, J.R., Prunuske, A.J., and Ullman, K.S. 2001. RNA association defines a functionally conserved domain in the nuclear pore protein Nup153. J. Biol. Chem. 276: 45349-45357.

Duricka, D. and Ullman, K.S. 2001. Analysis of RNA export using Xenopus oocytes. In Current protocols in cell biology (ed. J.S. Bonifacino et al.), pp. 11.14.1-11.14.13. John Wiley \& Sons, New York.

Fahrenkrog, B. and Aebi, U. 2002. The vertebrate nuclear pore complex: From structure to function. Results Probl. Cell Differ. 35: 2548.

Gwizdek, C., Bertrand, E., Dargemont, C., Lefebvre, J.C., Blanchard, J.M., Singer, R.H., and Doglio, A. 2001. Terminal minihelix, a novel RNA motif that directs polymerase III transcripts to the cell cytoplasm. Terminal minihelix and RNA export. J. Biol. Chem. 276: $25910-25918$.

Gwizdek, C., Ossareh-Nazari, B., Brownawell, A.M., Doglio, A., Bertrand, E., Macara, I.G., and Dargemont, C. 2003. Exportin-5 mediates nuclear export of minihelix-containing RNAs. J. Biol. Chem. 278: 5505-5508.

Hamm, J., Kazmaier, M., and Mattaj, I.W. 1987. In vitro assembly of U1 snRNPs. EMBO J. 6: 3479-3485.

Luo, M.J. and Reed, R. 1999. Splicing is required for rapid and efficient mRNA export in metazoans. Proc. Natl. Acad. Sci. 96: 1493714942. 
Marmier-Gourrier, N., Clery, A., Senty-Segault, V., Charpentier, B., Schlotter, F., Leclerc, F., Fournier, R., and Branlant, C. 2003. A structural, phylogenetic, and functional study of $15.5-\mathrm{kD} / \mathrm{Snu} 13$ protein binding on U3 small nucleolar RNA. RNA 9: 821-838.

Moroianu, J., Hijikata, M., Blobel, G., and Radu, A. 1995. Mammalian karyopherin $\alpha 1 \beta$ and $\alpha 2 \beta$ heterodimers: $\alpha 1$ or $\alpha 2$ subunit binds nuclear localization signal and $\beta$ subunit interacts with peptide repeat-containing nucleoporins. Proc. Natl. Acad. Sci. 92: 6532-6536.

Moroianu, J., Blobel, G., and Radu, A. 1997. RanGTP-mediated nuclear export of karyopherin alpha involves its interaction with the nucleoporin Nup153. Proc. Natl. Acad. Sci. 94: 9699-9704.

Morse, D.P., Aruscavage, P.J., and Bass, B.L. 2002. RNA hairpins in noncoding regions of human brain and Caenorhabditis elegans mRNA are edited by adenosine deaminases that act on RNA. Proc. Natl. Acad. Sci. 99: 7906-7911.

Nakielny, S., Siomi, M.C., Siomi, H., Michael, W.M., Pollard, V., and Dreyfuss, G. 1996. Transportin: Nuclear transport receptor of a novel nuclear protein import pathway. Exp. Cell. Res. 229: 261266.

Ohno, M., Segref, A., Kuersten, S., and Mattaj, I.W. 2002. Identity elements used in export of mRNAs. Mol. Cell 9: 659-671.

Pinol-Roma, S., Choi, Y.D., Matunis, M.J., and Dreyfuss, G. 1988. Immunopurification of heterogeneous nuclear ribonucleoprotein particles reveals an assortment of RNA-binding proteins. Genes \& Dev. 2: 215-227.
Rodrigues, J.P., Rode, M., Gatfield, D., Blencowe, B.J., Carmo-Fonseca, M., and Izaurralde, E. 2001. REF proteins mediate the export of spliced and unspliced mRNAs from the nucleus. Proc. Natl. Acad. Sci. 98: 1030-1035.

Rutjes, S.A., Lund, E., van der Heijden, A., Grimm, C., van Venrooij, W.J., and Pruijn, G.J. 2001. Identification of a novel cis-acting RNA element involved in nuclear export of hY RNAs. RNA 7: 741-752.

Saenger, W. 1984. Principles of nucleic acid structure. Springer-Verlag, New York.

Shah, S. and Forbes, D.J. 1998. Separate nuclear import pathways converge on the nucleoporin Nup153 and can be dissected with dominant-negative inhibitors. Curr. Biol. 8: 1376-1386.

Shah, S., Tugendreich, S., and Forbes, D. 1998. Major binding sites for the nuclear import receptor are the internal nucleoporin Nup153 and the adjacent nuclear filament protein Tpr. J. Cell. Biol. 141: 31-49.

Suntharalingam, M. and Wente, S.R. 2003. Peering through the pore. Nuclear pore complex structure, assembly, and function. Dev. Cell 4: 775-789.

Ullman, K.S. 2002. RNA export: Searching for mRNA identity. Curr. Biol. 12: R461-463.

Ullman, K.S., Shah, S., Powers, M.A., and Forbes, D.J. 1999. The nucleoporin nup153 plays a critical role in multiple types of nuclear export. Mol. Biol. Cell 10: 649-664.

Weis, K. 2003. Regulating access to the genome: Nucleocytoplasmic transport throughout the cell cycle. Cell 112: 441-451. 

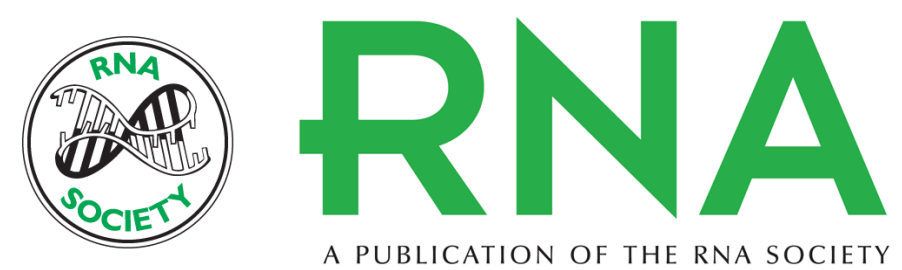

\section{The RNA binding domain within the nucleoporin Nup153 associates preferentially with single-stranded RNA}

JENNIFER R. BALL, CHRISTIAN DIMAANO and KATHARINE S. ULLMAN

RNA 2004 10: 19-27

References This article cites 24 articles, 16 of which can be accessed free at: http://rnajournal.cshlp.org/content/10/1/19.full.html\#ref-list-1

\section{License}

Email Alerting Receive free email alerts when new articles cite this article - sign up in the box at the Service top right corner of the article or click here. 